\title{
Análisis espacial y temporal de áreas quemadas en 1998, 2003 y 2015 en la Reserva de la Biosfera Montes Azules, Chiapas, México
}

\author{
Spatial and temporal analyses of burned areas 1998, 2003 and 2015 \\ in Montes Azules Biosphere Reserve, Chiapas, Mexico
}

\author{
Lilia L Manzo-Delgado ${ }^{\text {a*, }}$, José López-García ${ }^{\text {b }}$ \\ *Autor de correspondencia: ${ }^{a}$ Universidad Nacional Autónoma de México, Instituto de Geografía, \\ Laboratorio de Análisis Geoespacial, Circuito Investigación Científica s/n, Colonia Ciudad Universitaria, \\ Ciudad de México, México, C.P. 04510. tel.: (52-55) 56224334 ext.45501, 1lmanzo@igg.unam.mx \\ ${ }^{\mathrm{b}}$ Universidad Nacional Autónoma de México, Departamento de Geografía Física, Instituto de Geografía, \\ Ciudad de México, México.
}

\begin{abstract}
SUMMARY
In southeastern Mexico, forest fires threaten the biodiversity in tropical rainforests. The aim of this work was to analyze the spatial and temporal distribution of burned areas in Montes Azules Biosphere Reserve and its area of influence over three years: 1998, 2003 and 2015. The Normalized Burn Ratio (NBR) and the Burnt Area Index for MODIS (BAIM) were extracted from near-infrared and shortwave-infrared Landsat imagery; their accuracy was validated with ASTER images. As a result, 1,628 polygons of burned areas larger than 10 ha were delimited, covering 86,500 ha and representing $11.2 \%$ of the study area: $7.7 \%$ in $1998,3.2 \%$ in 2003 and $0.4 \%$ in 2015 . Burned areas of under 50 ha are of common occurrence each year, whereas the largest polygons (1,000 - 3,000 ha) are considered exceptional and are present only under the severe influence of El Niño weather phenomenon. The highest proportion of burned areas $(54.7 \%)$ affected agricultural lands, followed by secondary vegetation $(34 \%)$, tropical forests $(7.6 \%)$, temperate forests $(2.1 \%)$, savannah $(1 \%)$ and tular marshlands $(0.6 \%)$. Regarding burned areas, $20 \%$ occurred within the protected area. The decreasing tendency of burned areas confirms their relationship with the intensity of ENSO. Cartographic representation of burned areas is an effective means of evaluating the effects of fire management programs and biodiversity conservation of tropical rainforests in protected areas.
\end{abstract}

Key words: forest fires, burned areas, NBR index, BAIM, tropical rainforest.

\section{RESUMEN}

En el sureste de México, los incendios forestales constituyen una amenaza para la biodiversidad de las selvas tropicales húmedas. El objetivo de este trabajo fue analizar la distribución espacial y temporal de las áreas quemadas en la Reserva de la Biosfera Montes Azules y su zona de influencia, en tres años: 1998, 2003 y 2015. El método se basó en los índices NBR (Normalized Burn Ratio) y BAIM (Burnt Area Index for MODIS) derivados del infrarrojo cercano e infrarrojo de onda corta de imágenes Landsat, proceso validado con imágenes ASTER. Como resultado se delimitaron 1.628 polígonos de áreas quemadas mayores a 10 ha, cubriendo 86.500 ha que representan $11,2 \%$ del área estudiada: 7,7 \% en 1998, 3,2 \% en 2003 y 0,4 \% en 2015. Los polígonos menores de 50 ha fueron comunes en los diferentes años; y los de mayor extensión (1.000 - $3.000 \mathrm{ha}$ ) fueron excepcionales y solamente ocurrieron bajo la influencia severa del fenómeno meteorológico de El Niño. La superficie agropecuaria concentró la mayor proporción (54,7 \%), seguida por vegetación secundaria (34\%), selvas $(7,6 \%)$, bosques $(2,1 \%)$, sabana (1\%) y tular (0,6 \%). El área protegida concentró $20 \%$ de las afectaciones. La tendencia decreciente de las áreas quemadas confirma su relación con la intensidad del ENOS. La representación cartográfica de las áreas quemadas constituye una alternativa para evaluar los efectos de los programas de manejo del fuego y la conservación de la biodiversidad de las selvas tropicales húmedas en las áreas protegidas.

Palabras clave: incendios forestales, áreas quemadas, índice NBR, índice BAIM, selva tropical. 


\section{INTRODUCCIÓN}

El fuego es un componente crítico en la dinámica de los ecosistemas terrestres y las condiciones atmosféricas (Flannigan et al. 2009). La información derivada de las imágenes de satélite ha evidenciado la distribución de los incendios forestales, quemas agropecuarias y superficie afectada por el fuego a escala global. A nivel mundial se estima que el área quemada anual varía entre 273 y 567 millones de hectáreas, con un promedio de 383 Mha (Schultz et al. 2008); el $86 \%$ se presenta en pastizales y sabanas de África, Australia, Asia y América del Sur, el porcentaje restante ocurre en diversas coberturas forestales.

Las selvas tropicales húmedas son los ecosistemas terrestres con mayor diversidad de especies, cubren $10 \%$ de la superficie continental y proporcionan importantes servicios ambientales, su régimen de incendios natural es de baja frecuencia (cientos o miles de años); no obstante, cuando se presentan tienden a ser severos (Bowman et al. 2011). La gran mayoría de especies arbóreas de estos ecosistemas no poseen adaptaciones para tolerar los efectos del fuego; sin embargo, algunas de ellas puedes rebrotar después de los incendios (Rodríguez Trejo 2015). En las últimas décadas, los incendios forestales en las selvas tropicales han tenido un aumento considerable propiciado por una mayor intensidad del fenómeno de El Niño - Oscilación del Sur - ENOS (Rowel y Moore 2000), en combinación con la deforestación y el desarrollo agrícola (Cochrane 2003). En el planeta, cada día son destruidas 20.000 ha de selvas tropicales, muchas de ellas utilizando el fuego, provocando la extinción de numerosas especies (Estrada y Coates 2003). Debido a ello, los incendios forestales se consideran una amenaza para las selvas tropicales húmedas. Ante esta situación, las áreas protegidas juegan un papel relevante para conservar la gran biodiversidad de estos ecosistemas (Román-Cuesta y Martínez-Vilalta 2006).

Para enfrentar los incendios forestales en las regiones tropicales, se han realizado diversas acciones de prevención, alerta y control. Recientemente se han incorporado programas de manejo integral del fuego que combinan la importancia ecológica, cultural y socioeconómica, manteniendo un régimen deseable de los incendios (Myers 2006). También se cuenta con sistemas de monitoreo de incendios activos y detección de áreas quemadas a escala global derivados de información satelital, siendo uno de ellos el Fire information for Resource Management System - FIRMS (Giglio et al. 2016).

En México, cada año se presentan numerosos incendios forestales cuyo origen se atribuye tanto al uso tradicional del fuego en las actividades agrícolas y pecuarias, en combinación con la ocurrencia de fenómenos meteorológicos como los huracanes, que generan gran cantidad de material vegetal combustible, en combinación con periodos prolongados de sequía e incrementos de temperatura, ocasionados por el ENOS (Rowel y Moore 2000, Román-Cuesta y Martínez-Vilalta 2006). Los registros oficiales muestran una tendencia creciente a partir de la década de 1970, alcanzando un registro excepcional en la década de 1990, con 100.408 incendios y 2.676 .000 ha afectadas, cuyo incremento se relacionó con el intenso ENOS 1997-1998, que ocasionó uno de los mayores desastres a nivel nacional en 1998, con 14.408 incendios que afectaron 849.632 ha. Entre 2010 y 2017 se han acumulado 62.000 incendios y 3.070 .058 ha afectadas, identificando otro año catastrófico al 2011 con 12.040 incendios y 954.797 ha quemadas (CONAFOR 2017).

En la región sureste de México, los factores meteorológicos y de uso del fuego se combinan para favorecer la presencia de grandes incendios forestales en las selvas tropicales húmedas asociados a la presencia de ENOS intensos. En 1998 y 2003, las áreas naturales protegidas del estado de Chiapas registraron más de 30.000 ha afectadas por el fuego, constituyendo una amenaza para más de 5.000 especies vegetales, equivalentes a $17 \%$ de la flora de México (Román-Cuesta y Martínez-Vilalta 2006, Rodríguez Trejo 2015). Tomando como base los registros oficiales de incendios, se considera que las afectaciones ocurridas en las áreas protegidas del sureste se atribuyen a la falta de atención de las dependencias gubernamentales para prevenir y atender estos eventos (Román-Cuesta y Martínez-Vilalta 2006). Sin embargo, los registros oficiales proporcionan información muy general del número de eventos y superficie afectada. Debido a ello, se considera necesario conocer la ubicación espacial y temporal detallada de las áreas quemadas, constituyendo un apoyo excelente para estimar la probabilidad de ocurrencia de los incendios, evaluar la eficiencia de los programas de manejo y proporcionar un apoyo para la restauración de las áreas afectadas por el fuego.

Después de la severa temporada de incendios forestales de 1998 en México, se reforzaron numerosas acciones, entre las que destacan el programa nacional de protección contra incendios forestales (CONAFOR 2017); también se han desarrollado programas de alerta temprana para localizar los incendios con datos satelitales (Ressl et al. 2009); asimismo, se han incorporado programas de manejo integral del fuego en las áreas protegidas (CONANP 2011). De manera complementaria, se tiene un mapa nacional de incendios de gran relevancia a escala pequeña (1:8.000.000), para el periodo 2000-2014, elaborado con productos derivados de imágenes MODIS, que presenta la distribución y recurrencia de áreas quemadas de gran extensión (> 3.000 ha); en dicho mapa, la región sureste del país presenta escasas superficies quemadas porque los incendios son de menor extensión, siendo necesario utilizar imágenes de mayor resolución espacial como Landsat para analizar con mayor detalle la extensión y distribución de estos eventos (Manzo Delgado 2016).

Por más de dos décadas, las imágenes Landsat han sido utilizadas para detectar y cartografiar las áreas quemadas de manera detallada, utilizando la respuesta espectral de 
los depósitos de ceniza y carbón que se generan en la combustión del material vegetal y diferentes daños ocasionados en el dosel forestal. El proceso de detección combina la identificación visual del área quemada en compuestos de falso color RGB (por sus siglas en inglés) y la generación de los índices NBR (Normalized Burn Ratio) y BAIM (Burnt Area Index for MODIS), generados con las bandas del infrarrojo cercano e infrarrojo de onda corta de las imágenes Landsat (Bastarrika et al. 2011).

La detección de áreas quemadas con imágenes Landsat ha sido desarrollado en otras áreas protegidas y sus alrededores, tanto de México como en otros países. Sin embargo, la mayoría solo considera un evento o temporada, muy pocos analizan la distribución espacial de áreas quemadas en áreas protegidas y mucho menos realizan un análisis comparativo con la zona de influencia. En México, Jiménez Escudero (2017) generó la cartografía de áreas quemadas en el Área de Protección de Flora y Fauna Tutuaca, en el norte del país, periodo 2000-2015. Por otra parte, García Sampayo (2019) elaboró la cartografía de áreas quemadas para el Parque Nacional Iztaccihuatl-Popocatépetl y sus alrededores, en el centro del país, periodo 1998-2017.

En el ámbito internacional destacan los estudios realizados en la península Ibérica, África y América del sur. Días-Delgado et al. (2004) analizaron los patrones de incendios en Cataluña, España, durante 1975-1998, para mejorar el manejo forestal y los planes de conservación. Hudak y Brockett (2004) produjeron 22 mapas anuales de áreas quemadas, en el período 1972-2002, para la Reserva de Caza de Madikwe, entre Sudáfrica y Botswana. Liua et al. (2018) analizaron el periodo 2000-2016 para desarrollar un algoritmo para el monitoreo anual de áreas quemadas en Burkina Faso, África accidental, constituyendo un apoyo en la toma de decisiones en la gestión de la tierra. Antunes Daldegan et al. (2014) estudiaron el patrón espacial de áreas quemadas, periodo 2001-2010, dentro y fuera de la Reserva Natural Serra do Tombador, Brasil, cuya información reveló que los incendios más grandes ocurren en la zona de amortiguamiento alrededor del parque.

Los estudios nacionales e internaciones mencionados confirman el uso de imágenes Landsat para realizar análisis interanuales prolongados de áreas quemas en regiones templadas, mediterránea y el trópico seco; sin embargo, es difícil encontrar trabajos realizados las regiones tropicales.

La idea inicial del presente estudio era cubrir el periodo 1998 - 2015; sin embargo, la alta cobertura de nubes que caracteriza la región tropical del sureste del país generó serias limitaciones para contar con imágenes representativas de todo el periodo, específicamente en los meses de abril y mayor. Debido a ello, se decidió trabajar con dos años bajo influencia ENOS (1998 y 2003) y un año con ausencia de dicho fenómeno (2015).

En este contexto, el presente estudio tiene como objetivo realizar un análisis comparativo de las áreas quemadas en la Reserva de la Biosfera Montes Azules y una zona de influencia en 1998, 2003 y 2015, para evaluar la efectivi- dad de las áreas protegidas en la ocurrencia de incendios forestales en presencia y ausencia del ENOS. El análisis comparativo se basa en la utilización de índices dNBR y BAIM generados con imágenes de satélite Landsat. Los objetivos particulares son: (a) conocer la frecuencia, extensión y vegetación afectada en las áreas quemadas y (b) determinar la dinámica del fuego dentro y fuera del área protegida. Como hipótesis principal se plantea que el incremento en la frecuencia y extensión de las áreas quemadas de la región tropical del sureste de México está relacionado con las condiciones meteorológicas asociadas al ENOS y al uso tradicional de roza, tumba y quema, el cual ha sustituido la selva tropical por vegetación secundaria y terrenos agropecuarios, propiciando el establecimiento de especies tolerantes al fuego. Por tanto, se espera que a mayor severidad del ENOS, mayor será la frecuencia y extensión de las áreas quemadas en la vegetación secundaria y los terrenos agropecuarios, siendo menor en la selva tropical.

\section{MÉTODOS}

Área en estudio. La Reserva de la Biosfera Montes Azules (REBIMA) fue establecida el 12 de enero de 1978, con la finalidad de proteger la diversidad biológica de la región tropical en México y América Septentrional, además de promover el uso sostenible de los recursos naturales de la Selva Lacandona; asimismo, forma parte de la Red Internacional de Reservas del Programa del Hombre y la Biosfera (MAB) de la Organización de las Naciones Unidas para la Educación, la Ciencia y la Cultura (UNESCO) (INE 2000).

La Reserva de la Biosfera Montes Azules se ubica al este del estado de Chiapas $\left(90^{\circ} 44^{\prime} 4,80^{\prime \prime}\right.$ y $91^{\circ} 31^{\prime} 15,07^{\prime \prime}$ Longitud Oeste y $16^{\circ} 5^{\prime} 56,42^{\prime \prime}$ y $16^{\circ} 56^{\prime} 38,38^{\prime \prime}$ Latitud Norte), con una superficie de 327.706 ha (figura 1), administrativamente forma parte de los municipios de Ocosingo y Maravilla Tenejapa, la porción sur está delimitada por los ríos Lacantún, Jataté y Lacanjá (INE 2000). El programa de manejo (INE 2000) divide la reserva en cuatro zonas de manejo con actividades específicas, incluyendo el uso del fuego: en las zonas de protección (7 \%) y de uso restringido ( $71 \%$ ) no se permite el uso del fuego, ni actividades de aprovechamiento y explotación de los recursos naturales; en complemento, en las zonas de aprovechamiento sustentable de los recursos naturales $(22 \%)$ y de uso tradicional (1\%), se permite el uso del fuego en los terrenos agropecuarios (figura 1). La zona de influencia cubre una extensión de 442.635 ha, la cual está representada por una franja de $15 \mathrm{~km}$ de amplitud, con excepción de la porción sur, que cubre solo $1,5 \mathrm{~km}$ por estar en el borde con la frontera internacional con Guatemala; de forma específica, la zona de influencia no tiene restricciones en el uso del fuego. De esta manera, el área en estudio abarca un total de 770.341 ha, donde la REBIMA representa $42,6 \%$. 


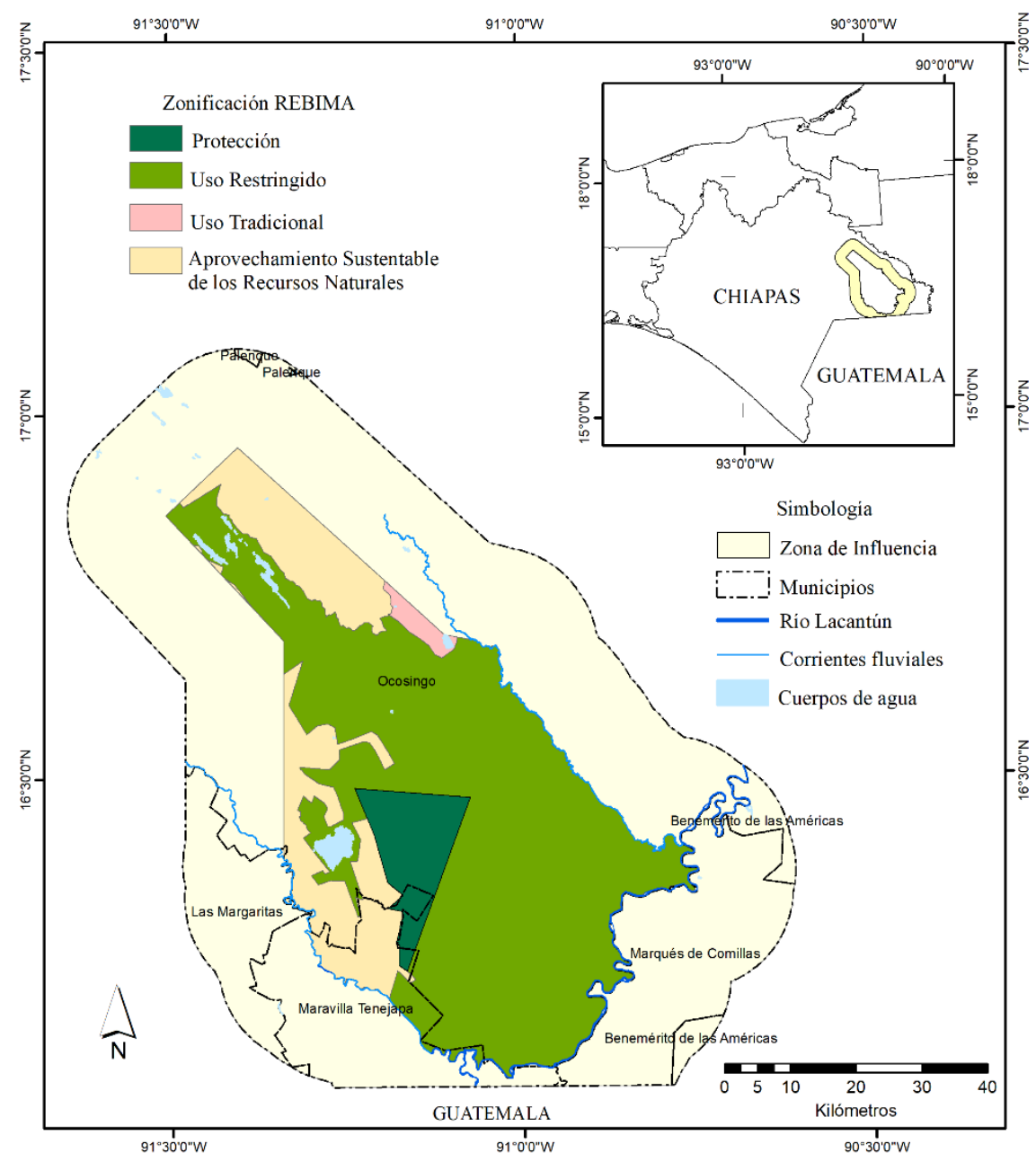

Figura 1. Reserva de las Biosfera Montes Azules (REBIMA) y su zona de influencia.

Montes Azules Biosphere Reserve (REBIMA) and its zone of influence.

Las variaciones topográficas en el área en estudio cubren un gradiente altitudinal entre $200 \mathrm{~m}$ y $1.500 \mathrm{~m}$, con relieve de origen cárstico dominado por sierras, lomeríos, cañadas $\mathrm{y}$ valles. En la región prevalece un clima cálido húmedo con abundantes lluvias en verano, la temperatura media anual varía entre 24 y $26^{\circ} \mathrm{C}$, la precipitación anual entre 2.500 y $3.500 \mathrm{~mm}$, representando una de las regiones más húmedas del país. Las condiciones topográficas y climáticas han favorecido el desarrollo de selva alta perennifolia y selva mediana subperennifolia, con algunas porciones de bosque de pino, bosque mesófilo de montaña, sabana y tular (INE 2000); asimismo, destaca la presencia de vegetación secundaria arbórea y arbustiva de selvas y bosques, entremezclados con pastizal inducido y agricultura (INEGI 2013).

La selva alta incluye árboles que alcanzan de 30 a $45 \mathrm{~m}$ de altura, cuyas especies típicas son Terminalia amazonia (J.F.Gmel.) Exell, Calophyllum brasiliense Cambess., Brosimum alicastrum Sw, Swietenia macrophylla King, Pouteria campechiana (Kunth) Baehni, Tabebuia guaya- can (Seem.) Hemsl., Dendropanax arboreus (L.) Decne. et Planch., Ficus glabrata Kunth, Manilkara zapota (L.) P. Royen, Ceiba pentrandra (L.) Gaertn. y Pithecellobium arboreum (L.) Urb. La mayoría de las especies vegetales presentan cortezas delgadas que les impide sobrevivir al fuego; sin embargo, algunas especies arbóreas, arbustivas y herbáceas presentan adaptaciones al fuego logrando recuperarse después de un incendio, ya sea por rebrote o recolonización, tal es el caso de Metopium brownei (Jacq.) Urb., Byrsonima crassifolia (L.) Kunth, Tabebuia rosea (Bertol.) DC. y M. zapota También se encuentran algunas palmeras como Astrocaryum mexicanum Liebm. ex Mart., Geonoma oxycarpa Mart. y Sabal mexicana Mart., al igual que el carrizo Equisetum hyemale var. affine (Engelm.) A.A. Eaton. Por otra parte, el helecho invasor Pteridium aquilinum (L.) Kuhn es un poderoso rebrotador, pues cuenta con una amplia red de rizomas. Asimismo, se ha observado que las áreas perturbadas por el fuego pueden ser colonizadas por Cecropia obtusifolia Bertol., Ochroma 
lagopus Sw., Cedrela odorata L. y Swietenia macrophylla King (Rodríguez Trejo 2015).

La vegetación de la reserva, al igual que el resto de la Selva Lacandona, desde la época precolombina hasta la actualidad, ha estado sometida a diversas formas de aprovechamiento y explotación forestal. En la segunda mitad del siglo XX se impulsó la producción agropecuaria y forestal, promovida por la inmigración de población estatal y nacional, lo que ha favorecido el crecimiento de la población y la fragmentación forestal (Ochoa-Gaona y González-Espinosa 2000). En el año 2000, había 64.152 habitantes y 251 localidades, en 2010 se registraron 81.553 habitantes y 271 localidades. En el mismo periodo la REBIMA triplicó la población, pasando de 6.496 habitantes en 2000 a 19.921 en 2010 y las localidades pasaron de 38 a 51 (INEGI 2010).

En las últimas décadas, el fenómeno ENOS ha sido más frecuente e intenso: muy fuerte en 1998, moderado en 2002-2003 y 2009-2010, débil en 2004-2007 (NOAA 2018). La intensidad del ENOS ha sido un factor importante en la ocurrencia de incendios relevantes. Durante 1998, en la REBIMA, los grandes incendios forestales afectaron 10.000 ha (INE 2000); en 2003, se registró otra temporada excepcional con 3.166 ha quemadas (López Portillo 2005).

Recopilación de información. Para conocer la distribución espacial y temporal de las áreas quemadas se reunieron los registros oficiales de incendios elaborados por la Comisión Nacional de Áreas Naturales Protegidas (CONANP) y la CONAFOR del estado de Chiapas. También fueron descargados los puntos de calor (incendios activos) detectados en imágenes de satélite; la información de 1998 se obtuvo de las imágenes nocturnas AVHRR-NOAA, con resolución espacial de $1,1 \mathrm{~km}$, la correspondiente a 2003 y 2015 fueron descargados del sistema FIRMS (EARTHDATA 2018a), los cuales se generan a partir de imágenes MODIS Terra/Aqua, con resolución de $1.000 \mathrm{~m}$. De esta manera, se reunieron 1.769 puntos de calor, los cuales fueron organizados en formato vectorial con apoyo de un sistema de información geográfica.

Las imágenes Landsat TM/ETM+/OLI (Path/Row 21/48; 21/49 y 20/49) se descargaron con apoyo del Visualizador Global del Servicio Geológico de Estados Unidos (USGS 2018). Se utilizaron 32 imágenes, preferentemente del primer semestre de cada año, en formato Geotiff, corregidas geométrica y radiométricamente (Level-1G), en proyección UTM (Universal Transverse Mercator). Las imágenes se calibraron radiométricamente para obtener los valores de reflectancia en la parte superior de la atmósfera (TOA) de las bandas ópticas; así mismo, se construyó una máscara de nubes y cuerpos de agua.

La distribución de la vegetación y uso del suelo, para cada año, se determinó mediante interpretación visual retrospectiva y prospectiva utilizando las imágenes Landsat descargadas previamente, tomando como base la cartografía nacional de vegetación y usos del suelo (serie V), escala 1:250.000 del año 2013 (INEGI 2013). Las categorías fueron agrupadas en las siguientes clases: bosques, incluyen bosque de pino y bosque mesófilo de montaña; selvas, agrupan selva alta perennifolia y selva mediana subperennifolia; vegetación secundaria, incluye la vegetación arbórea y arbustiva de bosques y selvas; sabana; tular (vegetación ubicada en las orillas de zonas lacustres) y uso agropecuario, que representa los terrenos de cultivo y pastizal inducido.

Detección y delimitación de las áreas quemadas. El análisis de las bandas espectrales sensibles para la detección de áreas quemadas ha resultado útil para el desarrollo de diversos índices, facilitando la delimitación del perímetro, estimación de los niveles de daño, caracterización de la vegetación afectada y análisis del patrón espacial y temporal. Los índices más utilizados para estos fines son el NBR y BAIM (Bastarrika et al. 2011), los cuales fueron seleccionados para este estudio, en combinación con interpretación visual comparativa.

Antes de generar los índices de área quemada se realizó una detección visual preliminar con apoyo de compuestos RGB 5 (15,5-17,5 $\mu \mathrm{m}) ; 4$ (7,50-9,00 $\mu \mathrm{m}) ; 3(6,30-$ $6,90 \mu \mathrm{m})$ y RGB $7(20,90-23,50 \mu \mathrm{m}) ; 4(7,50-9,00 \mu \mathrm{m})$; $3(6,30-6,90 \mu \mathrm{m})$ y sobreponiendo los puntos de calor AVHRR/MODIS en las fechas pre-incendio (enero - febrero), durante la temporada de incendio (marzo - junio) y post-incendio (julio - septiembre). Las áreas quemadas presentarán un color rojo oscuro o morado (figura 2), el cual está asociado a los residuos de carbón y ceniza depositados después de la combustión vegetal (Roy et al. 2005). Este proceso fue de gran utilidad para discriminar visualmente la respuesta espectral de las áreas quemadas en los compuestos RGB. La delimitación de algunos polígonos de área quemadas también se realizó para determinar, confirmar y ajustar los umbrales de los índices dNBR y BAIM.
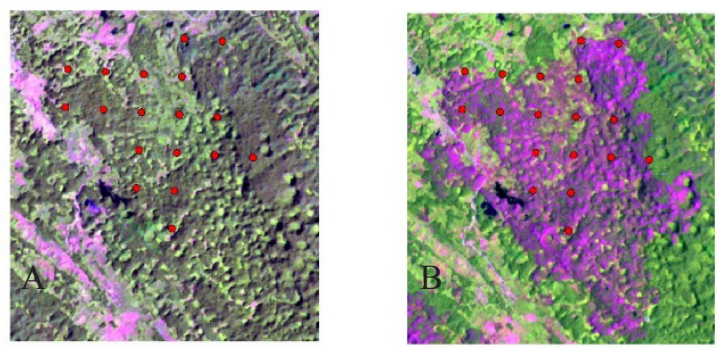

Figura 2. Compuestos de falso color RGB 543 en Landsat TM5: A) pre-incendio 17 de febrero 1998 B) pos-incendio 13 de septiembre de 1998, los círculos en color rojo son puntos de calor identificados en las imágenes AVHRR en mayo del mismo año.

Landsat TM 5 true-color image RGB 543: A) pre-fire $17 \mathrm{Fe}$ bruary 1998; B) post fire 13 September 1998; red circles represent hot spots extracted from AVHRR, May 1998. 
Una primera delimitación de área quemada se realizó con el índice NBR $=\rho \mathrm{NIR}-\rho \mathrm{SWIR} / \rho \mathrm{NIR}+\rho \mathrm{SWIR}$, donde $\rho=$ reflectancia, NIR $=$ infrarrojo cercano, $\mathrm{SWIR}=$ infrarrojo medio de onda corta. El NBR queda comprendido entre $-1 \mathrm{y}+1$; las áreas quemadas presentan valores negativos dependiendo de la severidad del fuego. Un marcado decremento entre el NBR anterior y posterior a la presencia de incendios facilitó la ubicación y delimitación de áreas quemadas. Tomando esto como referencia, se calculó el dNBR $=(\mathrm{b} 1-\mathrm{b} 2)$, donde: $\mathrm{b} 1=$ NBR pre-incendio y b2 = NBR pos-incendio (figura 3 ). El dNBR cubre un intervalo entre -2 y 2 ; los valores positivos $(>0,1)$ sugieren una mayor afectación que pueden ser clasificada según la severidad; los valores negativos $(<0,1)$ sugieren que la vegetación ha vuelto a crecer después del incendio; los valores cercanos a cero $(-0,1$ a 0,1$)$ son considerados no quemados (Key y Benson 2006).

La selección de umbrales dNBR para el área en estudio se realizó sobreponiendo los polígonos de área quema- da delimitados previamente por interpretación visual. El dNBR $>0,33$ fue considera un umbral mínimo para delimitar el área quemada. Los productos dNBR se calcularon entre las imágenes disponibles pre-incendio y post-incendio . En situaciones especiales, relacionadas con nubosidad y varios meses después del incendio, el umbral dNBR se incrementó a 0,58 o disminuyó a - 0,4 . Dependiendo de las escenas disponibles en cada uno de los tres path/row, cada año podía contar con dos o más dNBR. Los pixeles detectados como áreas quemadas fueron transformados en polígonos (capas vectoriales) para facilitar la creación de la cartografía anual.

Una segunda delimitación de área quemada se realizó con el índice el BAIM $=1 /(\rho c \text { SWIR }-\rho \text { SWIR })^{2}+(\rho c$ NIR $+\rho$ NIR $)^{2}$ donde: $\rho c$ SWIR $=$ reflectividad de un punto de convergencia de área quemada (0.5), $\rho c$ NIR = reflectividad de un punto de convergencia de área quemada (0.2), $\rho=$ reflectividad en las mismas bandas, $\mathrm{NIR}=$ infrarrojo cercano, SWIR $=$ infrarrojo medio de onda corta (Basta-
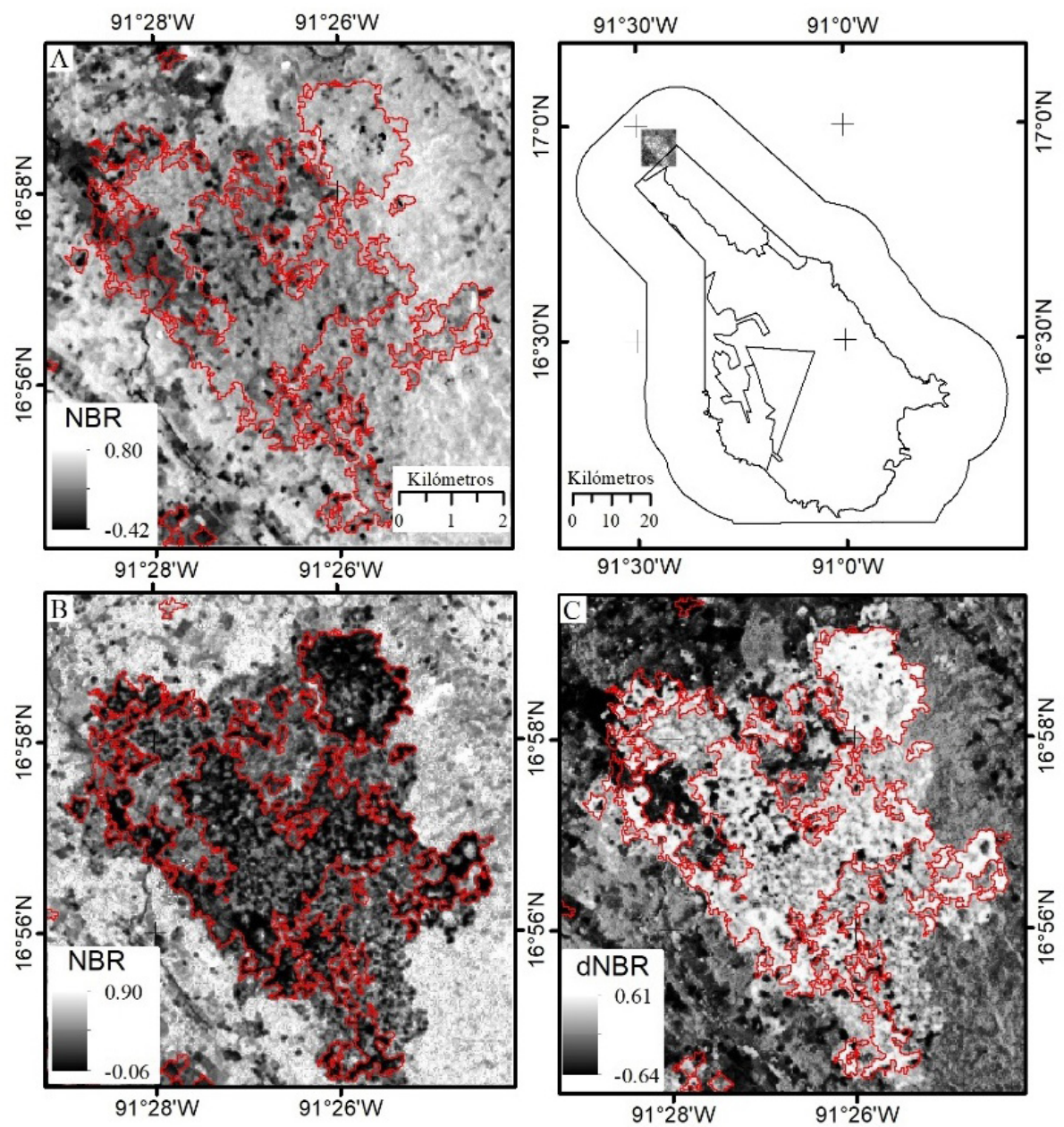

Figura 3. Índices NBR generados con Landsat TM5: A) 24 de mayo de 1998, B) post-incendio 13 de septiembre de 1998, C) índice dNBR calculado con las fechas anteriores. Las líneas en color rojo representan el límite final de área quemada.

NBR indices extracted from LandsatTM5: A) 24 May 1998; B) post-fires 13 September 1998; C) dNBR index calculated with the abovementioned dates. The red lines represent the final burned area limit. 
rrika et al. 2011). El producto BAIM presentan valores $>1$, cuyos umbrales para detectar las áreas quemadas varían según el tipo de vegetación y las condiciones ambientales; en el área en estudio los umbrales BAIM se ubicaron entre 30 y 60 (figura 4).

El BAIM se generó para todas las imágenes disponibles pre-incendio y pos-incedio de cada año (abril - septiembre). En el periodo en estudio, cada uno de los tres path/row incluyó con al menos tres imágenes BAIM. Los pixeles detectados como área quemada fueron transformados en polígonos (capas vectoriales) para facilitar la creación de la cartografía anual.

Cartografía anual de área quemada. La representación espacial de área quemada se generó con las capas vectoriales dNBR y BAIM. Para el año 1998, como primera etapa se unieron todos los vectores disponibles dNBR para las escenas del path/row 20/49; lo mismo se hizo para los path/row 21/48 y $21 / 49$, después se unieron los resultados dNBR de los tres path/row, posteriormente se realizó un recorte de la REBIMA y la zona de influencia. Un proceso similar se siguió para unir todos los vectores BAIM disponibles para los tres path/row del mismo año. Al final se unieron las capas vectoriales dNBR y BAIM de 1998, eliminado las superficies $<10$ ha. La cartografía correspondiente para 2003 y 2015 siguió el mismo procedimiento. Las áreas quemadas fueron caracterizadas como selva, bosque, sabana, tular, vegetación secundaria y uso agropecuario. Considerando el tamaño de los polígonos, se clasificaron en cuatro clases: $10-50$ ha, $50-100$ ha, $100-1.000$ ha y $1.000-3.000$ ha.

Validación. Para estimar el grado de confianza de los polígonos de área quemada se eligió el año 2003, el cual se consideró representativo del periodo en estudio. Para ello, se emplearon imágenes ASTER que han sido utilizadas en este tipo de evaluaciones (Anaya y Chuvieco 2012), cuya resolución espacial (píxeles de $15 \mathrm{~m}$ ) es mayor que la correspondiente a Landsat (pixeles de $30 \mathrm{~m}$ ). La adquisición de las imágenes ASTER se realizó por medio del Visualizador EARTHDATA (2018b). Se descargaron tres imágenes, con nubosidad $<70 \%$, en formato HDF, corregidas geométricamente (Level L1T), en proyección UTM. Las fechas corresponden al período final de la temporada de incendios, dos imágenes del 14 de mayo y una del 15 de junio del 2003, constituyendo materiales excelentes para validar las áreas quemadas detectadas en las imágenes Landsat.

Los polígonos de área quemada en las imágenes ASTER se delimitaron por interpretación visual en compuestos RGB: bandas $1(5,56 \mu \mathrm{m}), 2(6,61 \mu \mathrm{m})$ y $3(8,07 \mu \mathrm{m})$, donde las áreas afectadas se identificaron en tonos de color morado. La validación se basó en la comparación de los polígonos delimitados en ASTER y Landsat. Para ello, se eligieron 15 áreas de muestreo al azar en las imágenes ASTER, de forma rectangular, superficie variable, con una o más área quemada $>10$ ha. En cada área de muestreo se registró el número y tamaño de áreas quemadas Landsat, el tipo de vegetación y el número de puntos de calor MODIS. Los polígonos de área quemada delimitados en Landsat se sobrepusieron en el área de muestreo como un apoyo para delimitar los polígonos correspondientes en la imagen ASTER. Con ayuda de un SIG, se calculó la superficie total de los polígonos Landsat y ASTER, al igual que la superficie coincidente en ambos productos. La información obtenida en las áreas de muestro se organizó en 15 matrices de confusión para estimar los errores de omisión, los errores de comisión, el coeficiente Kappa.
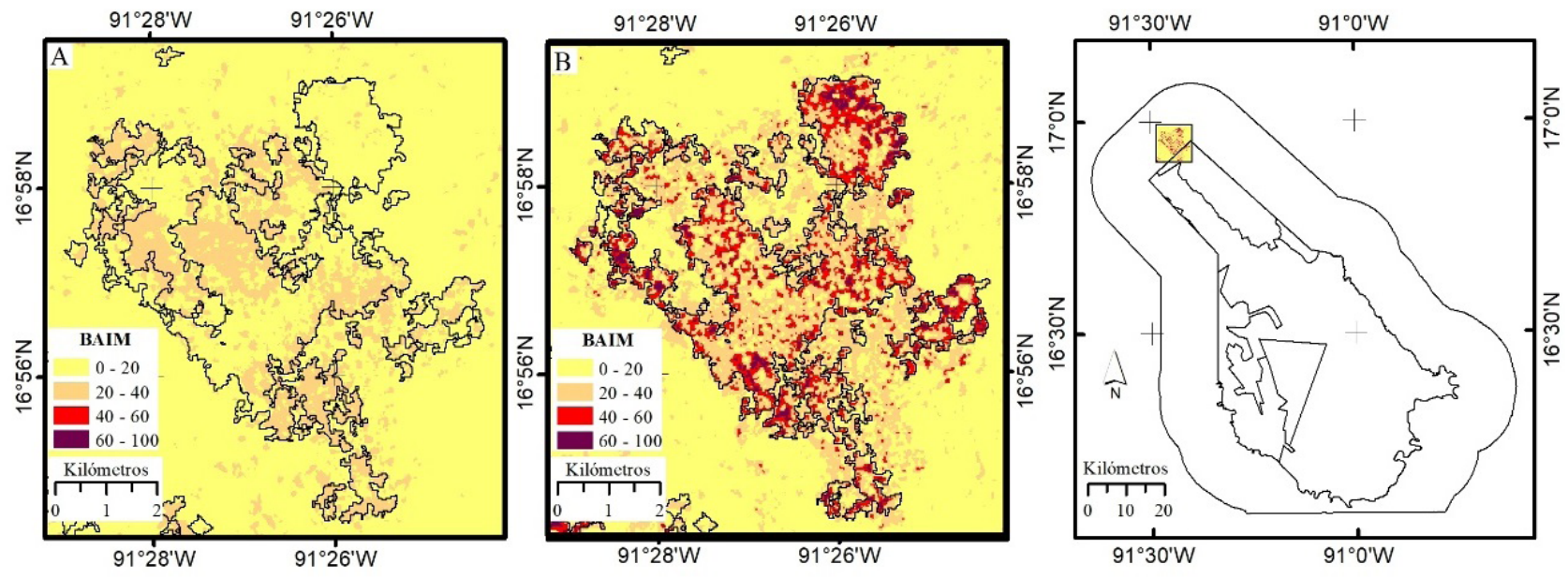

Figura 4. Índices BAIM generados con Landsat TM5: A) 24 de mayo de 1998, B) post-incendios 13 de septiembre de 1998. Las líneas en color negro representan el límite final de área quemada.

BAIMs extracted from Landsat TM 5: A) 24 May 1998; B) post-fires 13 September 1998. The black lines represent the final burned area limit. 


\section{RESULTADOS}

Frecuencia y extensión de las áreas quemadas. Se delimitaron 1.628 polígonos de área quemada que cubren 86.500 hectáreas y representan $11,2 \%$ del área en estudio. El promedio anual de los polígonos fue $543 \pm 380$ ha, para el caso del área quemada fue de $28.833 \pm 28.378$ ha. En el año 1998, ambas cifras se ubicaron por arriba del promedio anual; en tanto que, en 2003 y 2015 se situaron por debajo de estos. Asimismo, el año 1998 reunió 7,7 \% del total de área quemada, seguido por 2003 con 3,2\% y 2015 con $0,4 \%$. Considerando la clasificación de los polígonos de área quemada agrupadas según la superficie de afectación, en la clase 10 - 50 ha estuvo presente en los tres años; las clases 50 - 100 ha y $100-1.000$ ha predominaron en 1998 y 2003; en tanto que, la de mayor extensión 1.000 - 3.000 ha solo estuvo presente en 1998 (figura 5).

Distribución de las áreas quemadas. En los tres años analizados, la REBIMA acumuló 18.023 ha que representan $21 \%$ de la superficie total de área quemada, con un promedio anual de $6.008 \pm 6.240$ ha; la zona de influencia reunió 68.477 ha (79 \%) y promedio anual de $22.826 \pm 22.152$ ha. En 1998, dentro y fuera de la reserva estuvieron presentes todas las clases de área quemada; en 2003, estuvieron ausentes las áreas mayores de 1.000 ha; en 2015, la zona de influencia incluyó las mismas clases del año anterior, la REBIMA solo exhibió áreas quemadas menores de 50 ha (figuras 6 y 7 ).

En el periodo en estudio, la distribución anual de las áreas quemadas en las zonas de manejo de la REBIMA fue

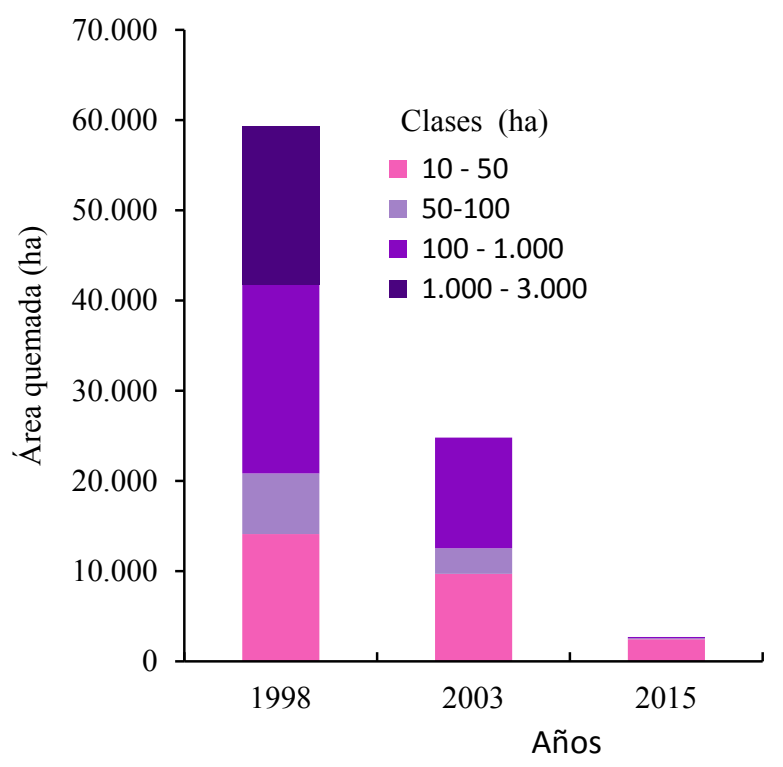

Figura 5. Área quemada anual clasificada por tamaño. Annual burned area classified by size. diferente. La zona de aprovechamiento sustentable de los recursos naturales acumuló 12.086 ha en el periodo en estudio (7.578 ha, 4.074 ha y 435 ha en 1998, 2003 y 2015, respectivamente); la zona de uso restringido concentró 5,555 ha (4.842 ha, 630 ha y 83 ha en cada año), la zona de protección reunió 381 ha ( 374 ha, 6 ha y 1 ha en cada año), la zona de uso tradicional registró 8 ha quemadas en 1998, ubicándose por debajo de la superficie mínima considerada (10 ha), motivo por el cual no tiene representación cartográfica.

Caracterización de las áreas quemada. En el área en estudio, los terrenos agropecuarios concentraron la mayor superficie de área quemada (47.342 ha), seguidos por la vegetación secundaria (29.401 ha), las selvas (6.617 ha) y los bosques (1.812 ha), cuyos promedios anuales fueron $15.781 \pm 13.430,9.800 \pm 11.402$ ha, $2.206 \pm 2.510$ ha, 604 \pm 953 , respectivamente; la sabana y el tular presentaron las menores afectaciones con 850 ha y 478 ha, con promedios anuales de $283 \pm 288$ y $159 \pm 181$, respectivamente. La proporción de área quemada anual, en los diferentes usos de suelo y vegetación, fue menor dentro de la REBIMA que en la zona de influencia (figura 8).

Validación de la detección de las áreas quemadas. Las 15 áreas de muestreo cubrieron una superficie total de 13.997 ha, con superficie promedio de $933 \pm 1.035$ ha, mismas que incluyeron 46 áreas quemadas en tres clases de tamaño: 38 en la clase 1 ( 10 - 50 ha), cinco de la clase 2 $(50-100 \mathrm{ha})$ y tres de la clase $3(100-1000 \mathrm{ha})$, las cuales se distribuyeron en diferentes tipos de vegetación: selva (s), vegetación secundaria (vs) y uso agropecuario (agp); además, 11 áreas de muestreo incluyeron entre 1 y 14 puntos de calor MODIS (cuadro 1).

Considerando las 15 matrices de confusión, se estimó que las áreas quemadas detectadas en las imágenes Landsat tienen un coeficiente Kappa promedio de 0,72 $\pm 0,1$ con error de omisión promedio de 19,62 \pm 8,64 y error de comisión promedio de $23,82 \pm 16,72$. El mayor valor Kappa fue 0,86 y el menor 0,55. Los menores errores de omisión $(2,66 \%)$ y comisión $(1,79 \%)$ se presentaron en selva y vegetación secundaria. El mayor error de omisión $(37,96 \%)$ se presentó en terrenos agropecuarios, en tanto que el mayor error de comisión (54,98 \%) se presentó en vegetación y selva (cuadro 1).

\section{DISCUSIÓN}

En las últimas décadas, las selvas tropicales húmedas del sureste de México han registrado incendios forestales de gran extensión considerándose una amenaza para la conservación de la biodiversidad de las áreas protegidas (Rodríguez Trejo 2015, Román-Cuesta et al. 2006). Sus causas se atribuyen a la presencia de fenómenos meteorológicos como el ENOS y la falta de atención de las dependencias gubernamentales (Román-Cuesta y MartínezVilalta 2006). Sin embargo, la delimitación de las áreas 

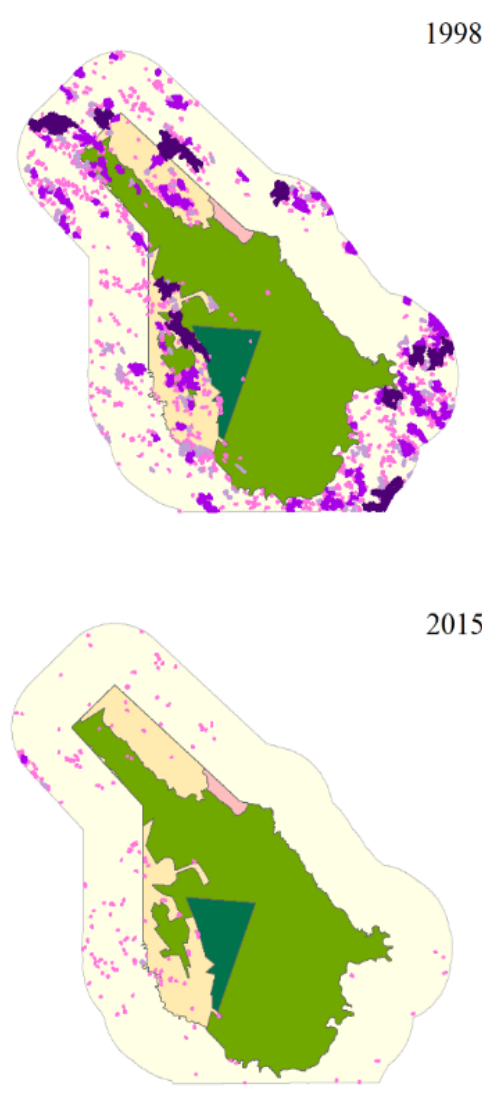

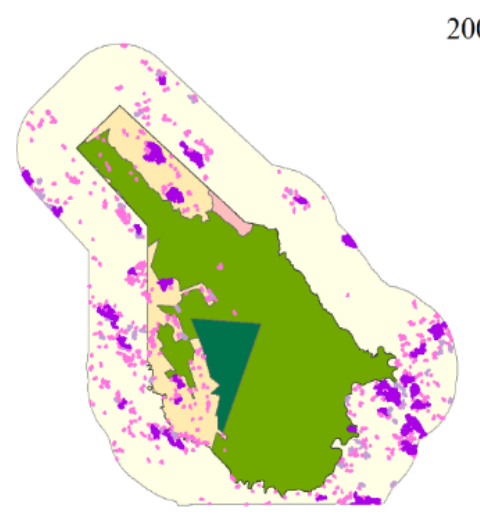

ÁREAS QUEMADAS

Clases de afectación (ha)

$10-50$

$50-100$

$100-1.000$

$1.000-3.000$

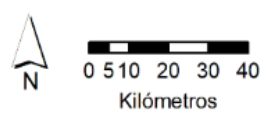

Figura 6. Distribución espacial y temporal de área quemada en la REBIMA y su zona de influencia, clasificada por tamaño. Spatial and temporal distribution of burned areas in Montes Azules Biosphere Reserve and its zone of influence, classified by size.

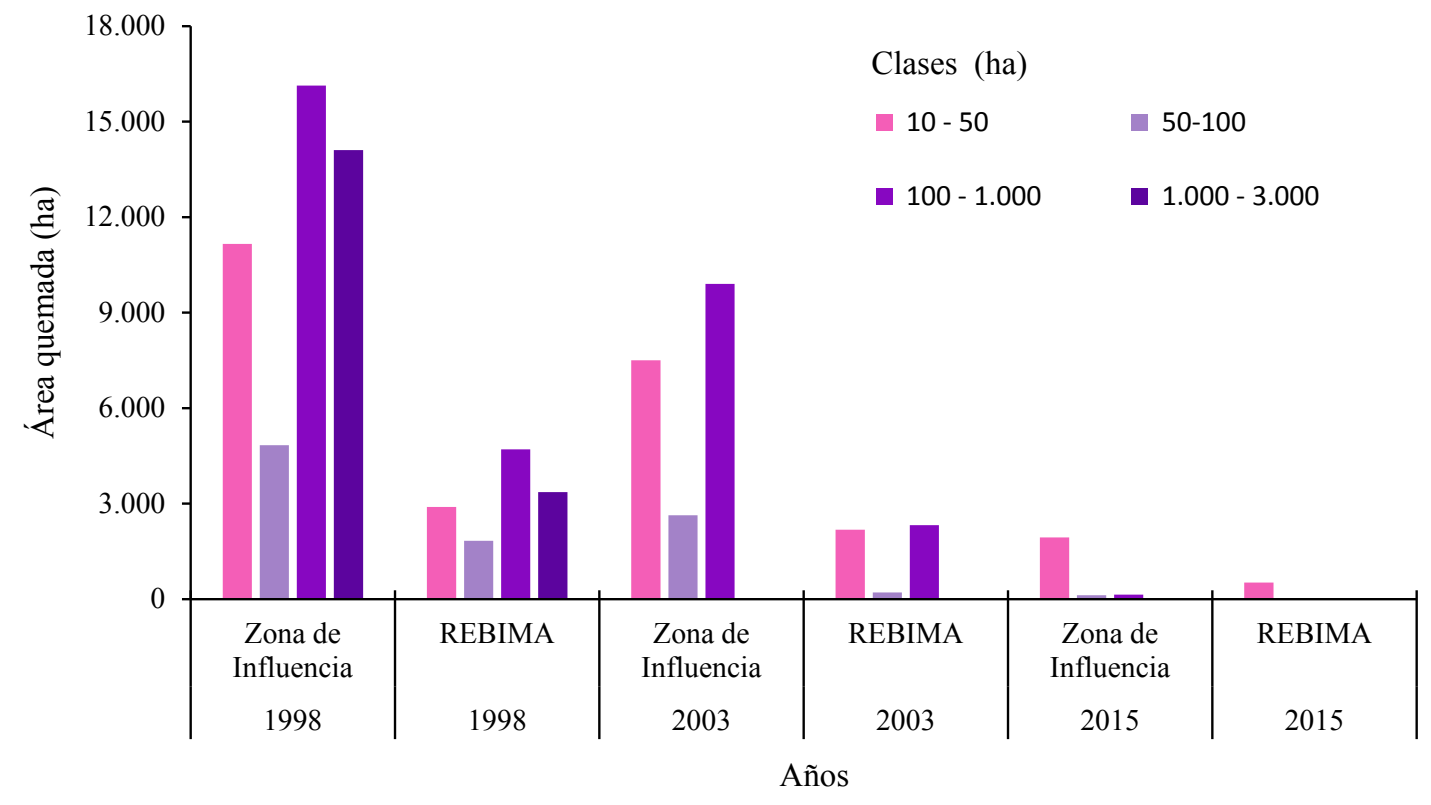

Figura 7. Área quemada anual clasificada por tamaño.

Annual burned area classified by size. 


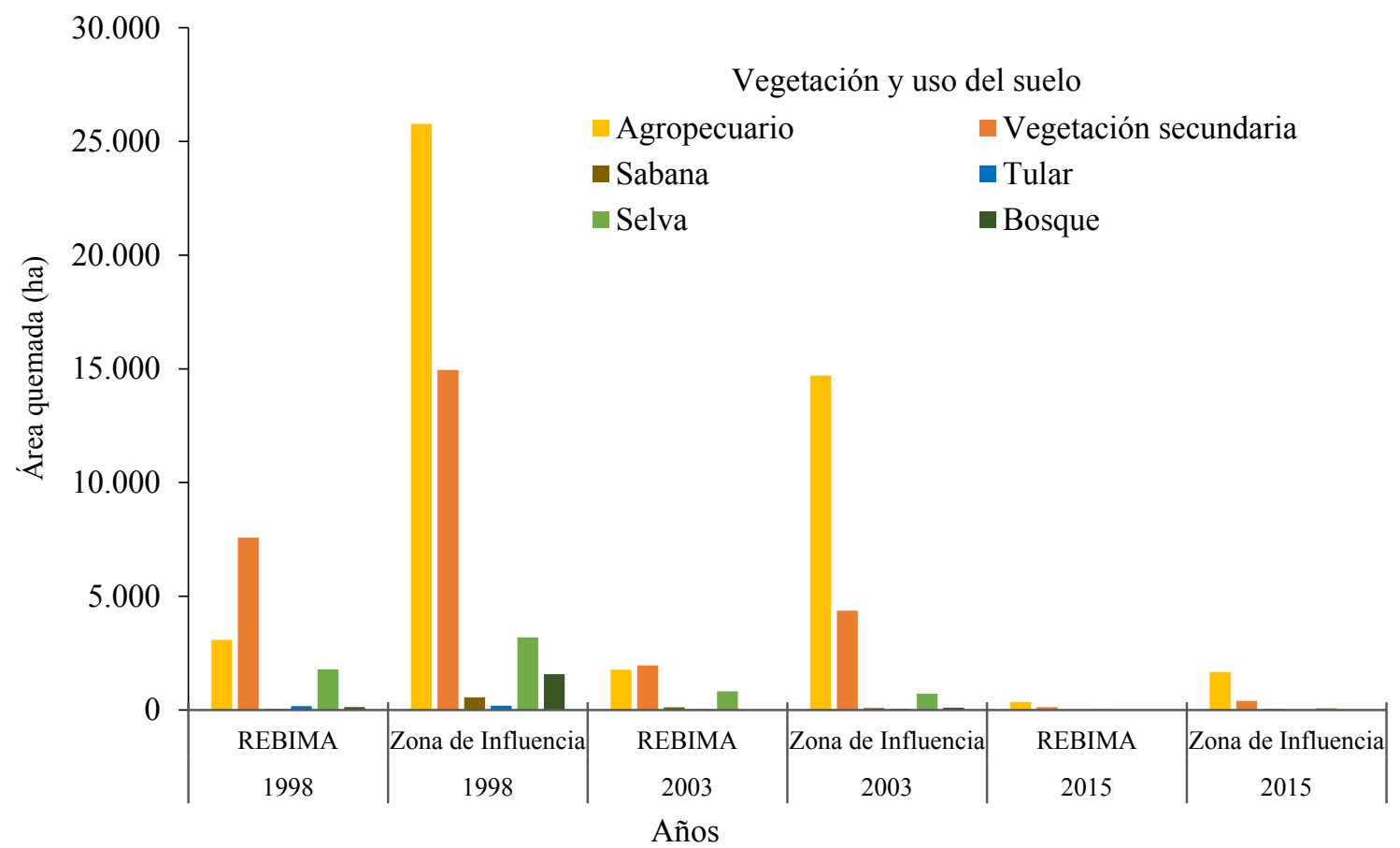

Figura 8. Área quemada anual clasificada por vegetación y uso del suelo.

Annual burned area classified by vegetation and land cover.

Cuadro 1. Resultados de las áreas de validación seleccionadas en las imágenes ASTER.

Results of the selected validation areas in the ASTER images.

\begin{tabular}{|c|c|c|c|c|c|c|c|c|c|}
\hline \multirow{2}{*}{$\begin{array}{l}\text { Superficie } \\
\text { (ha) }\end{array}$} & \multirow{2}{*}{$\begin{array}{l}\text { Imagen Aster } \\
\text { (2003) }\end{array}$} & \multicolumn{3}{|c|}{ Número de áreas quemadas ${ }^{1}$} & \multirow{2}{*}{$\begin{array}{l}\text { Vegetación y } \\
\text { uso del suelo }\end{array}$} & \multirow{2}{*}{$\mathrm{PC}^{3}$} & \multirow{2}{*}{$\begin{array}{l}\text { Error de } \\
\text { omisión \% }\end{array}$} & \multirow{2}{*}{$\begin{array}{l}\text { Error de } \\
\text { comisión \% }\end{array}$} & \multirow{2}{*}{$\begin{array}{l}\text { Índice } \\
\text { Kappa }\end{array}$} \\
\hline & & 1 & 2 & 3 & & & & & \\
\hline 991 & 14-may & 7 & & & agp & 2 & 19,89 & 40,55 & 0,63 \\
\hline 816 & 14-may & 3 & & & agp & 3 & 7,40 & 17,78 & 0,86 \\
\hline 583 & 14-may & 6 & & & agp & 0 & 21,53 & 24,89 & 0,75 \\
\hline 1.081 & 14-may & 4 & 1 & & vs, agp & 5 & 19,99 & 41,73 & 0,63 \\
\hline 748 & 14-may & 1 & & & vs, s & 1 & 17,53 & 54,98 & 0,55 \\
\hline 941 & 14-may & 3 & & & agp & 0 & 28,82 & 16,31 & 0,75 \\
\hline 394 & 14-may & 1 & 1 & & agp & 0 & 23,89 & 6,97 & 0,78 \\
\hline 4.531 & 14-may & 4 & & 2 & agp, vs & 14 & 26,58 & 11,18 & 0,76 \\
\hline 761 & 14-may & 1 & & & $\mathrm{~s}$ & 2 & 2,66 & 45,89 & 0,69 \\
\hline 406 & 14-may & 2 & & & agp & 2 & 37,96 & 36,19 & 0,56 \\
\hline 231 & 15 -jun & & & 1 & vs & 9 & 10,91 & 1,79 & 0,61 \\
\hline 213 & 15 -jun & 1 & & & $\mathrm{~s}$ & 0 & 18,38 & 7,07 & 0,86 \\
\hline 991 & 15 -jun & 2 & 1 & & vs & 11 & 20,63 & 4,07 & 0,85 \\
\hline 879 & 15-jun & 3 & 1 & & s, agp & 14 & 23,12 & 24,64 & 0,71 \\
\hline 433 & 15 -jun & & 1 & & vs & 3 & 15,06 & 23,27 & 0,76 \\
\hline
\end{tabular}

${ }^{1}$ Áreas quemadas clasificadas por tamaño (ha): 1 (10 - 50), 2 (50 - 100), 3 (100 - 1000).

${ }^{2} \mathrm{~s}=$ selva, vs $=$ vegetación secundaria, agp $=$ agropecuario.

${ }^{3} \mathrm{PC}=$ puntos de calor MODIS. 
quemadas utilizando imágenes de satélite y la generación de índices dNBR y BAIM ha puesto en evidencia que, en la Reserva de la Biosfera Montes Azules y la zona de influencia, durante los años 1998, 2003 y 2015, las áreas quemadas han seguido una tendencia decreciente que se atribuye no solo a la disminución de la intensidad del ENOS, sino también, al efecto positivo de los programas de manejo del fuego, los cuales han sido impulsados por organizaciones internacionales, federales, estatales y ONG (INE 2000, CONANP 2011), propiciado con ello la disminución de las quemas agropecuarias y con ello también los incendios forestales.

La respuesta espectral de la vegetación previa y posterior al incendio pone en evidencia el efecto del fuego en hojas, ramas y troncos quemados, en combinación con la acumulación de ceniza y carbón ocasionados por la combustión de materia orgánica, siendo responsables de la disminución en las longitudes de onda en el infrarrojo medio y el aumento en infrarrojo cercano, cuya variabilidad es registrada en los índices dNBR y BAIM, agilizando la detección y delimitación de áreas quemada (Key y Benson 2006, Bastarrika et al. 2011), condición que se confirma en este estudio. EL índice dNBR requiere de dos imágenes, una de pre-incendio y otra de pos-incendio; en tanto que el índice BAIM solo necesita una imagen pos-incendio. La utilización de ambos índices es altamente eficiente en las regiones tropicales húmedas con alta nubosidad, logrando utilizar solo uno ellos. En este contexto, cabe resaltar que la utilización de los puntos de calor FIRMS, derivados de MODIS (Giglio et al. 2016), son un apoyo importante durante la detección y la validación de las áreas quemadas. De esta manera, la distribución espacial y temporal de las áreas quemadas en el área en estudio, utilizando los índices dNBR y BAIM generados con imágenes Landsat, en combinación con los puntos de calor AVHRR y MODIS, confirma que son una alternativa confiable para conocer y analizar la dinámica de los incendios forestales.

Tomando como base los resultados del análisis de validación con imágenes ASTER, la confiabilidad es aceptable, semejante a la reportada por otros usuarios (Anaya y Chuvieco 2012), donde el promedio del valor Kappa presenta una desviación baja $(0,10)$. La variabilidad de los errores de omisión y comisión se atribuyen principalmente a las diferencias entre las fechas de las imágenes Landsat (28 de abril y 7 de mayo de 2003) y ASTER (14 de mayo y 15 de junio de 2003), en combinación con la presencia de nubes en ASTER, donde numerosas áreas quemadas quedaron cubiertas total o parcialmente con nubes.

La diferencia temporal entre las imágenes, con más de 15 días sin información, pone en evidencia que Landsat cubre gran parte de temporada de incendios; sin embargo, la falta de imágenes en mayo impide la delimitación de los incendios y quemas agropecuarias que ocurren al final de dicha temporada. También es importante considerar que en la señal post-incendio en la selva tropical desaparecer en pocas semanas. Debido a ello, los diferentes errores de omisión y comisión que registran las matrices de confusión guardan una estrecha relación con la señal efímera del fuego. Una alternativa para mejorar la confiabilidad de es utilizar imágenes satelitales con fecha más próxima a las imágenes Landsat.

Como se esperaba, la distribución espacial del área quemada es diferente en la REBIMA y la zona de influencia; donde la primera concentra solo una quinta parte de la superficie de afectación en terrenos agropecuarios y vegetación secundaria, siendo mínimas las afectaciones en selvas y bosques. Tales diferencias confirman la eficiencia del programa de manejo en esta área protegida (INE 2000), donde las quemas agropecuarias solo se permiten en la zona de aprovechamiento y uso tradicional, quedando prohibidas en la zona de uso restringido y la zona de protección. El cumplimiento de las normas de manejo se aprecia claramente en la distribución espacial y temporal de las áreas quemadas (figuras 6, 7 y 8). Con base en esto, se considera que tal situación ha favorecido una mejor conservación de las selvas tropicales en el área protegida; en tanto que, en la zona de influencia prevalece un mayor uso del fuego agropecuario, promovido a mediados del siglo pasado (Ochoa-Gaona y González-Espinosa 2000). La disminución de las áreas quemadas en la REBIMA también se atribuye a las acciones realizadas por la Secretaría de Medio Ambiente y Recursos Naturales a partir de 2004 para impedir nuevas invasiones de asentamientos irregulares y resolver la reubicación de las existentes fuera del área protegida (De la Maza 2010). Por otra parte, el reciente impulso de los programas de manejo del fuego en las áreas naturales protegidas del sureste constituye un elemento importante para conservar la biodiversidad de las selvas tropicales (CONANP 2011).

Es interesante corroborar que la extensión de las áreas quemadas está relacionada con la severidad del ENOS (NOAA 2018). De esta manera, bajo la influencia del ENOS intenso de 1998, las áreas quemadas en las selvas tropicales húmedas pueden alcanzar extensiones entre 1.000 y 3.000 ha; un ENOS moderado lograr afectaciones entre 100 y 1.000 ha; en tanto que, en ausencia de estos fenómenos, las áreas quemadas no rebasan las 50 ha.

La caracterización de las áreas quemadas en el área en estudio pone en evidencia que las superficies de mayor extensión ocurren preferentemente en vegetación secundaria arbórea y arbustiva derivada de las selvas tropicales húmedas, próximas a los terrenos agropecuarios, dentro y fuera de la reserva. Tal situación sugiere que este tipo de vegetación guarda una estrecha relación con las actividades de roza, tumba y quema, las cuales han propiciado la presencia de especies tolerantes al fuego como A. mexicanum, G. oxycarpa, S. mexicana, C. obtusifolia, O. lagopus y P. aquilinum (Rodríguez Trejo 2015) que son consideradas como indicadoras de incendios pasados.

De manera especial cabe resaltar la escasa presencia de áreas quemadas en la selva de la REBIMA, específicamente en las zonas de protección y uso restringido, lo cual con- 
firma la baja frecuencia de incendios forestales que caracteriza a esta comunidad vegetal (Cochrane 2003, Bowman et al. 2011). Esta situación también sugiere que la selva en esta área protegida presenta buen estado de conservación, con mínima presencia de especies tolerantes al fuego. Así mismo, es evidente que el amplio cauce del río Lacantún (>60 m) que recorre la reserva en el extremo sur, cumple una función excelente como barrera natural contra fuego, impidiendo que las intensas quemas agropecuarias de la zona de influencia se propaguen hacia la REBIMA (INE 2000).

Los resultados de este análisis evidencian que la extensión de las áreas quemadas en las regiones tropicales de México es menor a las que ocurren en los bosques templados en el centro y norte del país, cuya superficie varía entre 7.000 y 230.000 ha (Manzo Delgado 2016). Debido a ello, es necesario utilizar y adecuar técnicas de percepción remota e imágenes de satélite acorde a las características ambientales de cada región. Una alternativa para minimizar el problema de las nubes en las regiones tropicales es el uso de datos de radar Sentinel 1 disponibles a partir de 2014 y datos de Sentinel 2 que proporciona imágenes de alta resolución espectral (13 bandas: $10 \mathrm{~m}, 30 \mathrm{~m}$ y $60 \mathrm{~m}$ ) y temporal (5 días), disponibles a partir 2015 (DonezarHoyos et al. 2017).

El manejo integral de fuego ha jugado un papel importante en la reducción de incendios forestales constituyendo un apoyo para conservar la biodiversidad de la selva tropical, especialmente en la REBIMA, donde participan dependencias de gobierno y ONG (CONANP 2011). Así mismo, los habitantes de las comunidades locales han incorporado el manejo del fuego en el contexto del desarrollo sustentable (Myers 2006). En la actualidad, las áreas protegidas cuentan con mayor atención para enfrentar los incendios, muy diferente a lo sucedido a finales del siglo pasado, cuando el estado de Chiapas registró la mayor superficie afectada por incendios (Román-Cuesta y Martínez-Vilalta 2006).

Las cifras estimadas en este estudio se consideran diferentes a los registros oficiales (INE 2000, López Portillo 2005). En 1998, la superficie oficial considera 10.000 ha quemadas de cobertura forestal, en tanto que, las imágenes de satélite estiman 30.183 ha de bosque, selva, vegetación secundaria, sabana y tular; en el 2003, las cifras oficiales reportan 3.166 ha frente a 8.275 ha. Tales diferencias se atribuyen al tipo de vegetación considerada en cada estudio, siendo evidente que CONAFOR se enfoca principalmente en la cobertura de bosque y selva. Estas discrepancias enfatizan la necesidad de combinar ambas técnicas para agilizar y mejorar la representación y caracterización espaciotemporal de las áreas quemadas.

El método y los resultados del presente estudio se consideran semejantes a los realizados en otras áreas protegidas y sus alrededores, tanto de México como en otros países, constituyendo un aporte interesante para impulsar los estudios multitemporal de áreas quemadas con imáge- nes Landsat en las regiones tropicales. En México, el estudio elaborad por Jiménez Escudero (2017) en el Área de Protección de Flora y Fauna Tutuaca, Chihuahua. Por otra parte, el estudio realizado por García Sampayo (2019) en el Parque Nacional Iztaccihuatl-Popocatépetl y Zoquiapan y sus alrededores, evaluó el efecto de los incendios en la densidad de la cobertura foresta. Los resultados del presente estudio destacan la importancia de incluir la distribución espacial y temporal de las áreas quemadas dentro y fuera de las áreas protegidas para evaluar la efectividad de las áreas protegidas en la ocurrencia de incendios.

\section{CONCLUSIONES}

Las imágenes Landsat son una alternativa eficiente para analizar la distribución espacial y temporal de las áreas quemadas en la Reserva de la Biosfera Montes Azules y una zona de influencia.

La delimitación de las áreas quemadas utilizando los índices NBR y BAIM, permite conocer su frecuencia, extensión, vegetación afectada por el fuego y comprender su dinámica en presencia de fenómenos meteorológicos asociados al ENOS.

Las áreas quemadas menores de 50 ha, son comunes en los diferentes años; mientras que las mayores de 1.000 ha solo ocurren en presencia de ENOS severo. La presencia de extensas áreas quemadas en vegetación secundaria arbórea y arbustiva de la selva tropical húmeda, es una respuesta de las quemas agropecuarias. La tendencia decreciente de las áreas quemadas entre 1998-2015 confirma su relación con la presencia del ENOS y los programas de manejo del fuego.

La distribución espacial y temporal de las áreas quemadas es diferente en la REBIMA y la zona de influencia; donde la primera concentra solo una quinta parte de la superficie afectada. Tales diferencias confirman que, en la REBIMA el uso restringido del fuego es una estrategia eficiente para disminuir la ocurrencia de incendios forestales severos, constituyendo un papel relevante para la conservación de la biodiversidad de la selva tropical húmeda dentro de las zonas de protección y uso restringido.

Debido a ello, el análisis de la distribución espacial y temporal de las áreas quemadas debe ser un elemento imprescindible en los programas de manejo de las áreas naturales protegidas.

\section{REFERENCIAS}

Anaya JA, E Chuvieco. 2012. Accuracy assessment of burned area products in the Orinoco basin. Photogrammetric Engineering \& Remote Sensing 78(1): 53-60. DOI: https://doi. org/10.14358/PERS.78.1.53

Antunes Daldegan G, OA de Carvalho, R Fontes Guimarães, RA Trancoso Gomes, F de Figueiredo Ribeiro, C McManus. 2014. Spatial Patterns of Fire Recurrence Using Remote Sensing and GIS in the Brazilian Savanna: Serra do Tombador Nature Reserve, Brazil. Remote Sensing 6 (2014): 
9873-9894. DOI: https://doi.org/10.3390/rs6109873

Bastarrika A, E Chuvieco y MP Martín. 2011. Mapping burned area from Landsat TM/ETM+ data with a two-phase algorithm: Balancing omission and commission errors. Remote Sensing of Environment 115(2011): 1003-1012. DOI: https://doi.org/10.1016/j.rse.2010.12.005

Bowman DMJS, J Balch, P Artaxo, WJ Bond, M Cochrane, CM D'Antonio, R Defries, FH Johnston, JE Keeley, M Krawchuk, C Kull, M Mack, M Morit, S Pyne, CI Roos, AC Scott, NS Sodhi, TW Swetnam, R Whittaker. 2011. The human dimension of fire regimes on Earth. Journal of Biogeography 38(12): 2223-2236. DOI: https://doi.org/10.1111/ j.1365-2699.2011.02595.x

Cochrane MA. 2003. Fire science for rainforests. Nature 421(6926): 913-919. DOI: https://doi.org/10.1038/nature 01437

CONAFOR (Comisión Nacional Forestal, MX). 2017. Reportes de incendios. Comisión Nacional Forestal. Consultado 22 sep. 2018 Disponible en http://www.cnf.gob.mx:8090/snif/ portal/las-demas/reportes-de-incendios-forestales

CONANP (Comisión Nacional de Áreas Naturales Protegidas, MX). 2011. Estrategia y lineamientos de manejo del fuego en áreas naturales protegidas. México D.F. México. CONANP. 36 p. Consultado 22 sep. 2018 Disponible en http://www.camafu.org.mx/wp-content/uploads/2017/12/ estrategia de manejo_del_fuego_ANP.pdf

De la Maza J. 2010. Reserva de la Biosfera Montes Azules. In Carabias J, J Sarukhán, J de la Maza, C Galindo eds. Patrimonio natural de México. Cien casos de éxito. México, D.F., México. Comisión para el Conocimiento y Uso de la Biodiversidad. p. 30-31.

Díaz-Delgado R, F Lloret, X Pons. 2004. Spatial patterns of fire occurrence in Catalonia, NE, Spain. Landscape Ecology 19: 731-745. DOI: https://doi.org/10.1007/s10980-005-0183-1

Donezar-Hoyos U, A Larrañaga-Urien, A Tamés-Noriega, C Sánchez-Gil, L Albizua-Huarte, R Ciriza-Labiano, F del Barrio-Arellano. 2017. Applicability of Sentinel-1 and Sentinel-2 images for the detection and delineation of crisis information in the scope of Copernicus EMS services. Revista de Teledetección (50): 49-57. DOI: https://doi. org/10.4995/raet.2017.8896

EARTHDATA. 2018a. Fire Information for Resource Management System (FIRMS). Consultado 6 abr. 2018. Disponible en https://earthdata.nasa.gov/data/near-real-time-data/firms

EARTHDATA. 2018b. Earthdata Search. Consultado 6 abr. 2018. Disponible en http://search.earthdata.nasa.gov.

Estrada A, R Coates-Estrada. 2003. Las selvas tropicales húmedas de México. Recurso poderoso, pero vulnerable. La ciencia para todos 132. México, D.F., México. Fondo de Cultura Económica. 194 p.

Flannigan MD, MA Krawchuk, WJ de Groor, BM Wotton, LM Gowman. 2009. Implications of changing climate for global wildland fire. International Journal of Wildland Fire 18: 483-507. DOI: https://doi.org/10.1071/WF08187

García Sampayo JC. 2019. Teledetección de áreas quemadas asociadas a incendios forestales en la Sierra Nevada, México (1998-2017). Ciudad de México, México. Facultad de Filosofía y Letras, Universidad Nacional Autónoma de México. $87 \mathrm{p}$.

Giglio L, W Schroeder, CO Justice. 2016. The collection 6 MODIS active fire detection algorithm and fire products. Remo- te Sensing of Environment 178(2016): 31-41. DOI: https:// doi.org/10.1016/j.rse.2016.02.054

Hudak AT, BH Brockett. 2004. Mapping fire scars in a southern African savanna using Landsat imagery. International Journal of Remote Sensing 25(16): 3231-3243. DOI: https://doi. org/10.1080/01431160310001632666

INE (Instituto Nacional de Ecología, MX). 2000. Programa de manejo de la Reserva de la Biosfera Montes Azules. Instituto Nacional de Ecología. México, D.F., México. 256p. Consultado 22 sep. 2018. Disponible en http://www.paot. $\underline{\mathrm{mx} / \text { centro/ine-semarnat/anp/AN29.pdf }}$

INEGI (Instituto Nacional de Estadística, Geografía e Informática, MX). 2013. Conjunto de datos vectoriales de uso de suelo y vegetación escala 1:250 000, serie V (capa unión), escala: 1:250000. Edición: 2a. Consultado 22 sep. 2018. Disponible en http://www.beta.inegi.org.mx/temas/mapas/ usosuelo/

INEGI (Instituto Nacional de Estadística, Geografía e Informática, MX). 2000 y 2010. Censo de población y vivienda. Consultado 22 sep. 2018. Disponible en http://www.beta. inegi.org.mx/proyectos/ccpv/2010/

Jiménez Escudero VM. 2017. Teledetección de superficies quemadas asociadas a incendios forestales entre 2000-2015 en el Área de Protección de Flora y Fauna Tutuaca, Chihuahua. Tesis Maestría en Geografía. Ciudad de México, México. Facultad de Filosofía y Letras, Universidad Nacional Autónoma de México. 98 p.

Key CH, NC Benson. 2006. Landscape assessment: Sampling and analysis methods. In FIREMON: Fire effects monitoring and inventory system. Lutes DC, RE Keane, JF Caratti, CH Key, NC Benson, S Sutherland, LH Gangi eds. USDA Rocky Mountain Research Station, General Technical Report 164. (Fort Collins, CO). p. LA1-LA51.

Liua J, J Heiskanena, EE Maedab, PKE Pellikkaa. 2018. Burned area detection based on Landsat time series in savannas of southern Burkina Faso. International Journal of Applied Earth Observation Geoinformation 64 (2018):210-220. DOI: https://doi.org/10.1016/j.jag.2017.09.011

López Portillo A. 2005. Detección, prevención y manejo del fuego mediante la gestión local y regional de las ANP's de la Región Frontera Sur de la CONANP. Ecobiosfera El Triunfo S.C., Informe final SNIB-CONABIO proyecto No. DQ012. México D. F. Consultado 22 sep. 2018 Disponible en http://www.conabio.gob.mx/institucion/proyectos/resultados/InfDQ012.pdf

Manzo Delgado LL. 2016. Incendios forestales de gran relevancia en México: algoritmos y sensor MODIS para su detección y monitoreo In Moncada Maya JO, A López López eds. Geografía de México. Una reflexión espacial contemporánea. México, D.F. México. Instituto de GeografíaUNAM. p. 310-322.

Myers RL. 2006. Iniciativa global para el manejo del fuego. Tallahasee, Florida. U.S.A. The Nature Conservancy. 28 p. Consultado 22 sep. 2018 Disponible en https://www.conservationgateway.org/Documents/el_manejo_integral_del fuego.pdf

NOAA (National Oceanic and Atmospheric Administration and National Weather Service, US) 2018. Historical El Niño/ La Niña episodes (1959-presente). Consultado 22 sep. 2018 Disponible en http://www.cpc.ncep.noaa.gov/products/ precip/CWlink/MJO/enso.shtml\#history 
Ochoa Gaona S, M González Espinosa. 2000. Land use and deforestation in the highlands of Chiapas, Mexico. Applied Geography 20(2000): 17-42. DOI: https://doi.org/10.1016/ $\underline{\mathrm{S} 0143-6228(99) 00017}$

Ressl R, G López, I Cruz, RR Colditz, M Schmidt, S Ressl, R Jiménez. 2009. Operational active fire mapping and burnt area identification applicable to mexican nature protection areas using Modis and NOAA-AVHRR direct readout data. Remote Sensing of Environment 113(2009): 1113-1122. DOI: https://doi.org/10.1016/j.rse.2008.10.016

Rodríguez Trejo DA. 2015. Incendios de vegetación: su ecología, manejo e historia Volúmenes 1 y 2. Guadalajara, Jalisco, México. Printing Arts México. 1705 p.

Román-Cuesta RM, J Martínez-Vilalta. 2006. Effectiveness of Protected Areas in Mitigating Fire within Their Boundaries: Case Study of Chiapas, Mexico. Conservation Biology 20(4): 1074-1086. DOI: https://doi.org/10.1111/j.15231739.2006.00478.x

Rowell A, PF Moore. 2000. Global Review of Forest Fires.
Gland, Switzerland. WWF/IUCN. 66p. Consultado 22 sep. 2018. Disponible en https://portals.iucn.org/library/sites/ library/files/documents/2000-047.pdf

Roy DP, PGH Frost, CO Justice, T Landmann, JL Le Roux, K Gumbo, S Makungwa, K Dunham, R Du Toit, K. Mhwandagara, A. Zacarias, B Tacheba, OP Dube, JMC Pereira, P Mushove, JT Morisette, SK Santana Vannan, D Davies. 2005. The Southern Africa Fire Network (SAFNet) Regional Burned-Area Product-Validation Protocol. International Journal of Remote Sensing 26 (19): 4265-4292. DOI: https://doi.org/10.1080/01431160500113096

Schultz MG, A Heil, JJ Hoelzemann, A Spessa, K Thonicke, JG Goldammer, AC Held, JMC Pereira, M van het Bolscher. 2008. Global wildland fire emissions from 1960 to 2000. Global Biogeochem 22: 1-17. DOI: https://doi. org/10.1029/2007GB003031

USGS (United States Geological Survey, US). 2018. Global Visualization Viewer. Consultado 9 feb. 2018. Disponible en http://glovis.usgs.gov 